\title{
SENSING SIBERIA
}

Passion for Life: Emotions, Feelings and Perception in the North and Siberia. 10th Siberian Studies Conference. Saint Petersburg, October 24-26, 2016.

The organisers of this year's Siberian Studies Conference invited scholars to discuss a variety of topics relating to the emotional dimension of Siberia and the Russian North.* The managing team attempted to open the topic to a wide range of researchers and proposed themes connected to emotions from every possible point of departure: marriage, kinship, taboos, social rules, language, memory, power, industrial development, landscape and tourism. Instead of a widespread approach to Siberian indigenous cultures through the discourse of technology and rationality, traditional knowledge of the environment and communication with spirits and souls, the conference was conceptualised (as one could read from the call of papers) around northern laughter and tears, screams and whispers, around affection and dislike, love and hate. The hesitation of scholars to study or even to take into account Arctic feelings and lack of academic tools to explore the sense of Siberia inspired the convenors to provoke the academic community to start thinking collaboratively about these topics.

The main organisers of the event came from the Department of Siberian Ethnography at the Museum of Anthropology and Ethnography (Kunstkamera), Saint Petersburg. The venue of the conference was the Russian Geographical Society, which facili- tated the proper emotional framework for the whole event with its solid history in Nordic exploration. The co-president of the organising committee, Vladimir Davydov, admitted in his opening speech that the theme of emotion in the North was risky for such a prominent international scientific event. But notwithstanding this, the organisers managed to receive more than one hundred applications for presentations. However, it also became evident in the course of the conference that scholars felt slightly insecure with this thematic paradigm. The overall feeling was that the papers presented somehow constituted an incomplete whole, as researchers were not always completely sure what to talk about. Similar hesitation also ruled in the audience's mind.

For example, after the presentation about BAM (the Baikal-Amur Mainline, a 4,300-km-long railway line constructed between the 1930s and 1980s, one of the most lauded, but also controversial, construction projects in the Soviet Union), delivered by Olga Povoroznyuk and Peter Schweitzer, an experienced voice from the audience raised the rhetorical question: "Was our heroism ideological or real?" And the same voice from the epic past gave us a methodological piece of advice: "Romanticism must be estimated objectively." A particular view on the role and style of science claims that

* Art Leete participated at the conference within the framework of projects financed by the Estonian Research Council (grant no. 590) and the ERA.Net RUS Plus Programme (grant no. 189, CORUNO). 
no space can be left for obscure emotion in research, and neither in life. We see that the deconstruction of emotions is especially complicated in cases where the delicate but straightforward feelings of real people are involved.

As the reader may already have guessed, the conference was by no means an unexciting scholarly meeting. In the course of the forum twelve thematic sessions and round tables, the screening of documentary films, and two plenary lectures were arranged. In addition to which we had the opportunity to enjoy a display of folk art items made by indigenous artisans from the Taimyr Peninsula, and musical performances by Nganasan musicians.

Nikolai Ssorin-Chaikov, from the Higher School of Economics in Saint Petersburg and Andrei Golovnev from the Ural Branch of the Russian Academy of Sciences in Yekaterinburg delivered the plenary lectures. Ssorin-Chaikov employed the anthropological notion of the 'affective turn' and explored the spontaneous reactions of his indigenous field partners, the reindeer herders of the Siberian Far North. Ssorin-Chaikov stressed the need to conduct micro-ethnography and to concentrate on cultural practice in particular settings and unexpected situations that may last just for a few minutes. Ssorin-Chaikov argued that an exploration of affects enables us to reveal "the microtopography of mutual relationships" that is related to wider social field and reciprocal economic practices.

Andrei Golovnev discussed the emotions of the Arctic nomads from a rather different angle. Golovnev explored reindeer herders' experience against the background of the universal conceptual frame of power, sex, kinship, freedom, prestige and faith. In his analysis Golovnev concentrated on different emotion-related motifs that drive nomad behaviour in everyday life situations, as well as their general emotionally loaded life philosophy.
Conference sessions were dedicated to the topics of museums and memory, tastes and smells, discomfort during field encounters, feasts and rituals, industrialisation and mobility, kinship, political and economic strategies, language and oral history. These themes were discussed within the framework of emotion, which connected all reports in a more or less conventional whole. Particular topics ranged from the Siberian indigenous peoples' shamanic rituals and folk orthodox religious symbols, to food and alcohol consumption, practices of collective work and festivals, to perception of the landscape, animals and humans in the North.

This almost incomprehensible assortment of presentations indicates that emotions penetrate all aspects of human experience in the Arctic. But it also reflects the problem that the habit of discussing the emotional effects of the North on human behaviour is not yet settled in the studies of Siberia and the Russian North. The whole event was bound together by the intellectual excitement of the participants and overwhelming enthusiasm of the conference convenors, especially that of Dima Arzyutov.
Art Leete (University of Tartu) 